\title{
The relationship between empowerment and the adoption of total quality management: From the point of view of top and middle leaders in Al Baraka Bank of Algeria.
}

\author{
Mr. Rebie Messaoud \\ Assistant Lecturer, Faculty of Economics ,commerce and management University, Setif-ALGERIA.
}

\begin{abstract}
This study aims to know the dimensions of empowerment effect on the adoption of total quality management in the Algerian Al Baraka Bank of the pond. the study addressed to the leaders in the upper and middle levels in the bank only. Through the study, we found that $71 \%$ of the independent variable explain the dependent variable empowerment adoption of total quality management from the standpoint of administrative leaders in the Algerian AL Baraka Bank.

Key words: total quality management, empowerment, Critical factors TQM, adoption of total quality management.
\end{abstract}

\section{INTRODUCTION}

Essential in the total quality approach is the strong focus on employee involvement. Unlike the traditional mechanistic approach, employee knowledge and contributions, are viewed as a prerequisite. Examples of total quality performance demonstrate the importance of employee involvement, since "the only point at which true responsibility for quality can lie is with the person or group actually doing the job. Hence, TQM rests on employee involvement but conversely also improves the quality of employee working life. Research about impact of TQM programs shows that success not so much depends on aspects of technical rationality, such as improved measurement or policies, but more crucially depends on conditions related to employee behavior, culture and leadership. (J.A.P. Hoogervorst et all, 2005 ) In the achievement of total quality in the organization the human resource dimension is very important (Deming, 1982, 1986, five of Deming's 14 points relate directly to the notion of involvement and empowerment (Rahman, 2002). According Ishikawa, Feigenbaum, Harrington, Juran Total quality management as well as various organizational development initiatives relating to teams, empowerment, and other concepts that have the potential of improving all aspects of a business. (Mildred Golden Pryor et all,2001) likewise, Many of the basic elements of TQM involve people, such as teamwork, participative management, creativity, effective communication, customer feedback, employee involvement and empowerment, employee and management trust and support (Therese A. Joiner, 2007). TQM should promote empowerment of front-line employees, giving them more responsibility and information, and so undermining middle managers" traditional role in implementing and monitoring the instructions of top management. (Alireza Shahraki, et all, 2011) Finally, found that organizational trust and empowerment have a strong relationship with the propensity of employees to remain within the organization (Alireza Shahraki , et all, 2011)

\section{LITERATURE OF TQM}

TQM was initially developed in Japan, and has been further developed in the United States (US) and United Kingdom (UK). During the 1980s and 1990s TQM began to influence other National Business Systems (NBSs) and was widely seen as a revolution in management methods. Public policy over the last three decades has been influenced by ideas offered from New Right ( Alexandros G. -2007)TQM is a set of systematic activities carried out by the entire organization to effectively and efficiently achieve the organization's objectives so as to provide products and services with a level of quality that satisfies customers, at the appropriate time and price The Application Guide for The Deming Prize 2013 TQM is a general philosophy of management that attempts to maximize the competitiveness of an organization through the continual improvement of the quality of its products, services, people, processes and environments. There are many definitions of TQM; interestingly, no single definition can express the whole picture Alireza Shahraki, et all, 2011. Quality can be defined as "the degree to which the product in use will meet the expectations of the customer" (Feigenbaum, A.V. 1961) (Feigenbaum, 1961), or simply defined as "conformance to requirements" (Crosby, 1979). In addition, states that TQM is an attempt to improve the whole organization's competitiveness, effectiveness, and structure (Oakland, J., 1993). Continuous improvement (Edward Sallis, 2002) TQM is a practical but strategic approach to running an organization that focuses on the needs of its customers and clients. It rejects any outcome other than excellence. TQM is not a set of slogans, but a deliberate and systematic 
approach to achieving appropriate levels of quality in a consistent fashion that meet or exceed the needs and wants of customers. It can be thought of as a philosophy of continual improvement only achievable by and through people. (Edward Sallis , 2002) TQM is not about working to someone else's agenda, unless your customers and clients have specified the agenda. It is not something that only senior managers do and then pass their directions down the line. The total in TQM dictates that everything and everybody in the organization is involved in the enterprise of continuous improvement. The management in TQM likewise means everyone, because everyone in the institution, whatever their status, position or role, is the manager of their own responsibilities. This is a difficult idea to put across, and it is the reason why some organizations talk, as RollsRoyce do, about Total Quality rather than TQM (Edward Sallis, 2002)

\section{LITERATURE OF EMPOWERMENT}

Concept of empowerment has been considered by authorities in all organizations during the recent years because of rapid environmental changes and researchers have always paid attention to employees' empowerment in public and private sectors. This concept was represented in the 1980's for the first time but researchers, academicians and authorities of management and organizations considered it in the 1990's. Education too hasn't been immunized versus such transformations and hence experts of this scope along with experts of other scopes have started researches in education organization (Sayyed Mohsen Allameh et al, 2012). The definitions of empowerment it self vary widely across scholars. Many studies define empowerment as intrinsic task motivation for example Conger \& Kanungo, 1988; Thomas \&Velthouse, 1990) or motivation reflective of the person-environment fit (Zimmerman,1990). Theory Youth empowerment involves a collective, democratic, and prosocial process of engagement through which young people participate in program decisionmaking (Cargo, Grams, Ottoson, Ward, \& Green, 2003; Jennings, Parra-Medina, Messias, \& McLoughlin, 2006) (M.H. Morton, P. Montgomery 2012). There is general encouragement to give employees sufficient latitude in their work-definition and authority to be able to apply the full breadth of ability to the overall aims of the company(T M Williams, 1997). According to Blanchard (1997) empowerment has been described as the breaking down of traditional hierarchical structures. (S. Nauman et al. 2010) Empowerment is also transferring power and responsibility to employees so that, within specified limits, they will be able to provide the best possible customer service at their own discretion (Amarjit Gill, Alan B. 2010). Bowenand Lawler's (1992) discussion of empowerment relates the concept to practice that includes sharing information, rewards, knowledge and power with front line employees. Employers give front line, non- managerial employees, those described by Bateson and Hoffman (1999) as "boundary-spanning workers" mediating between the organization and its customers, opportunities to make their own decisions and to develop their abilities and job performance skills (C. Cheung et al. 2012) Thomas and Velthouse (1990) conceptualize empowerment as a set of four task assessments or cognitions that individuals make as they attempt to interpret their work situation.

The four dimensions of empowerment include meaning, impact, competence, and choice (T.H. Sigler, C.M. Pearson 2000)

Meaning: when he/she believes that work is meaningful and is given greater responsibilities (Weichun Zhu and All, 2012)

Competence: according to Thomas \& Velthouse (1990) have defined competency as the degree that an individual can perform his job duties skil fully and successfully. Empowered individuals feel personal superiority and believe that they can learn and grow in order to encounter with new challenges' (Sayyed Mohsen Allameh et al,2012)

Impact: is assessed as a belief that one can influence others' work and decisions at all levels. Competence is an individual's belief in his or her ability to perform activities with skill (T.H. Sigler, C.M. Pearson, 2000)

Self-determination: shows one's feelings of autonomy in making decisions in areas such as work methods, time, pace, and effort (Weichun Zhu and All ,2012)

\section{RESEARCH HYPOTHESES}

a. Problematic: Is there a relationship between physiological empowerment and adopting the total quality management from the standpoint upper and middle administrative leadership in Al Baraka Bank of Algeria?

b. Objective: This study attempts to reach the relationship possibilities between physiological empowerment and total quality management in Al Baraka Bank of Algeria.

c. Hypotheses:

-There is a relationship between physiological empowerment of employees and adopting TQM.

-There is relationship between dimensions of physiological empowerment (Meaning, Competence, Selfdetermination and Impact) and adopting TQM .

d. Method :Figure 1: shows the theoretical framework of this research. The Dependent Variable in this study is physiological empowerment. The Dependent Variable Psychological of Empowerment based on Spreitzer (1995, 1996) study. and the independent Variable adopting TQM. The study is attempted to show the 
relationship between empowerment and adopting TQM. The leader's age, gender, educational level, and position are used as control variables.

Figure 1: Figure 1 shows the dependent variable and the independent variable.

\begin{tabular}{|c|l|}
\hline Empowerment & Critical factors TQM \\
Meaning / Self-determination & Top management, Strategic \\
Competence & Planning, Customer Focus, \\
Effective communication, \\
Evaluation, Training, involve \\
employees, motivation.
\end{tabular}

4.5 Measurement: To measure psychological empowerment a scale developed by Spreitzer (1995) was used. Four dimensions of empowerment were assessed: meaning /self-determination (6 items), competence (4 items), and impact ( 3 items). Likewise a measure critical factor TQM .was used eight dimensions :Top management (6 items), Strategic Planning (4 items), Customer Focus (5 items), Effective communication (4 items), Evaluation (7 items), Training ( 7 items), involve employees ( 7 items) and motivation (6 items). All items were measured on a five-point Likert scale where $1=$ strongly disagree and $5=$ strongly agree. Demographic questions on gender, age, and work experience were also included in the second part of the questionnaire. The questionnaire was translated form English to Arabic using a back translation methodology. Prior to data collection, a pilot study was conducted with a sample of 20 employees from different firm. Based on the pre-test, several items were revised and some changes were made to the questionnaire format.

4.6 Data collection and analysis: The data were collected from a sample of Top management and middle management working in Algerian Barak Bank. A total of 100 questionnaires were distributed to employees. Of these 100 questionnaires, 67 usable questionnaires were returned and used in the analysis. Data analysis included descriptive analysis and multiple regression linear. All tests were performed using SPSS.

\section{DISCUSSION THE RESULTS}

Sample characteristics: This section is mainly concerned with presenting a descriptive analysis of the sample characteristics. reported by respondents showed $70.2 \%$ of respondents were male and only $29.8 \%$ were female. $12.6 \%$ of survey respondents were 30 years of age and under, $71,3 . \%$ were between 30 and 50and $16.1 \%$ were 50 or over others. The score of employees on all four dimensions Meaning / Self-determination (mean= 2.27, S.D = 0.65), Competence (mean= 2.64, S.D = 0.9), Impact (mean= 2,36, S.D = 0.67) was Less average. Descriptive statistics for total quality management factor have shown that employees score on TQM was Less average $($ mean $=2.41, \mathrm{~S} . \mathrm{D}=0.75) \quad($ mean $=2.37$, S.D $=0.69)$.

Table1: Model Summary

\begin{tabular}{|l|l|l|l|l|}
\hline \multicolumn{4}{|c|}{ Model Summary $^{\mathrm{b}}$} \\
\hline Model & $\mathrm{R}$ & R Square & Adjusted R Square & Std. Error of the Estimate \\
\hline 1 & $.623^{\mathrm{a}}$ & .389 & .382 & .59055 \\
\hline $\begin{array}{l}\text { a. Predictors: (Constant), meaning /self-determination } \\
\text { b. Dependent Variable critical factors to adopt TQM }\end{array}$ \\
\hline
\end{tabular}

Table2: Coefficients

\begin{tabular}{|c|c|c|c|c|c|c|}
\hline \multicolumn{7}{|c|}{ Coefficients $^{\text {a }}$} \\
\hline \multirow{2}{*}{\multicolumn{2}{|c|}{ Model }} & \multicolumn{2}{|c|}{ Unstandardized Coefficients } & Standardized Coefficients & \multirow[t]{2}{*}{$\mathrm{t}$} & \multirow[t]{2}{*}{ Sig. } \\
\hline & & B & Std. Error & Beta & & \\
\hline \multirow[t]{2}{*}{1} & Constant & .787 & .230 & & 3.415 & .001 \\
\hline & Meaning & .717 & .097 & .623 & 7.352 & .000 \\
\hline
\end{tabular}

The regressions results of meaning /self-determination and adopting TQM As clearly seen from Table 1et 2 that the prediction models are all significant ( $\mathrm{p}$. value $<0.005)$ and dimension of meaning /self-determination for 38.9 percent of the variance $\left(\mathrm{r}^{2}=0.389, \mathrm{~F}=54.04\right)$ in adopting TQM

Table3: Model Summary

\begin{tabular}{|l|l|l|l|l|}
\hline \multicolumn{5}{|c|}{ Model Summary $^{\text {b }}$} \\
\hline Model & R & R Square & Adjusted R Square & Std. Error of the Estimate \\
\hline 1 & $.777^{\text {a }}$ & .604 & .599 & .47523 \\
\hline a. Predictors: (Constant), competence \\
\hline b. Dependent Variable: : critical factors to adopt TQM \\
\hline
\end{tabular}


Taple4: Coefficients

\begin{tabular}{|l|l|l|l|l|l|l|l|}
\hline \multicolumn{2}{|l|}{ Model } & \multicolumn{2}{l|}{ Unstandardized Coefficients } & Standardized Coefficients & \multirow{2}{*}{ S } & Sig. \\
\cline { 3 - 5 } \multicolumn{2}{l|}{} & B & Std. Error & Beta & & \\
\hline \multirow{2}{*}{1} & Constant & .713 & .158 & & 4.510 & .000 \\
\cline { 2 - 5 } & competence & .644 & .057 & .777 & 11.390 & .000 \\
\hline
\end{tabular}

The regressions results of competence and adopting TQM As clearly seen from Table 3 et 4 that the prediction models are significant $(\mathrm{p}$. value $<0.005)$ and dimension of competence for 60.4 percent of the variance $\left(\mathrm{r}^{2}=\right.$ $0.604, \mathrm{~F}=129.72)$ in adopting TQM

Taple5: Model Summary

\begin{tabular}{|l|l|l|l|l|}
\hline \multicolumn{4}{|l|}{ Model Summary $^{\mathrm{b}}$} \\
\hline Model & $\mathrm{R}$ & R Square & Adjusted R Square & Std. Error of the Estimate \\
\hline 1 & $.718^{\mathrm{a}}$ & .516 & .510 & .52555 \\
\hline a. Predictors: (Constant), Impact \\
\hline
\end{tabular}

Taple6: Coefficients

\begin{tabular}{|l|l|l|l|l|l|l|l|}
\hline \multicolumn{2}{|l|}{ Model } & \multicolumn{2}{|l|}{ Unstandardized Coefficients } & Standardized Coefficients & \multirow{2}{*}{ S } & \\
\cline { 3 - 5 } \multicolumn{1}{l|}{} & B & Std. Error & Beta & & \\
\hline & (Constant) & 1.106 & .149 & & 7.440 & .000 \\
\cline { 2 - 8 } & Impact & .553 & .058 & .718 & 9.517 & .000 \\
\hline
\end{tabular}

The regressions results of Impact and adopting TQM As clearly seen from Table 5 et 6 that the prediction models are all significant (p. value < 0.005) and dimension of Impact for 51.6 percent of the variance $\left(\mathrm{r}^{2}=\right.$ $0.516, \mathrm{~F}=90.56)$ in adopting TQM

Table 7: Model Summary

\begin{tabular}{|l|l|l|l|l|l|}
\hline \multicolumn{5}{|c|}{ Model Summary $^{\mathrm{b}}$} \\
\hline Model & $\mathrm{R}$ & R Square & Adjusted R Square & Std. Error of the Estimate & Durbin-Watson \\
\hline 1 & $.845 \mathrm{a}$ & .714 & .704 & .40880 & .904 \\
\hline a. Predictors: (Constant), Impact, Meaning, competence \\
\hline
\end{tabular}

Table 8: Coefficients

\begin{tabular}{|c|c|c|c|c|c|c|c|c|}
\hline \multicolumn{9}{|c|}{ Coefficients $^{a}$} \\
\hline \multirow{2}{*}{\multicolumn{2}{|c|}{ Model }} & \multicolumn{2}{|c|}{ Unstandardized Coefficients } & \multirow{2}{*}{$\begin{array}{c}\begin{array}{l}\text { Standardized } \\
\text { Coefficients }\end{array} \\
\text { Beta } \\
\end{array}$} & \multirow[t]{2}{*}{$\mathrm{t}$} & \multirow[t]{2}{*}{ Sig. } & \multicolumn{2}{|c|}{ Collinearity Statistics } \\
\hline & & B & Std. Error & & & & Tolerance & VIF \\
\hline \multirow[t]{4}{*}{1} & (Constant) & .247 & .170 & & 1.450 & .151 & & \\
\hline & Meaning & .283 & .081 & .246 & 3.474 & .001 & .687 & 1.456 \\
\hline & competence & .390 & .068 & .471 & 5.745 & .000 & .513 & 1.950 \\
\hline & Impact & .209 & .064 & .271 & 3.251 & .002 & .497 & 2.014 \\
\hline
\end{tabular}

The regressions results of empowerment and adopting TQM As clearly seen from Table 7 et 8 that the prediction models are all significant $(\mathrm{p}<0.005)$ and dimensions of empowerment for 71.4 percent of the variance $\left(r^{2}=.714, F=69.05\right)$ in adopting TQM, and collinearity statistics represent fit model (Tolerance less than 10 , VIF less than 3 )

\section{CONCLUSION}

Applied study showed that there is a relationship between the dimensions of empowerment and the adoption of total quality management. and that there is a variation in the impact of each dimension. That variation came the first competence and second impact and finally meaning and self-determination and this result can be interpreted that the leaders in senior administrators and middle leaders do not care much about the dimension meaning / self-determination for the adoption of TQM, in which they see that there is great importance of impact and competence to adopt TQM. But generally the perspective of administrative leaders elevated to the overall dimensions of empowerment and their relationship to the adoption of total quality management. 


\section{References:}

[1]. J.A.P. Hoogervorst et all, PERSPECTIVES Total quality management The need for an employee- centred, coherent approach, The TQM Magazine Vol. 17 No. 1, 2005 pp. 92-106.

[2]. Mildred Golden Pryor et all, What Management and Quality Theories Are Best for Small Businesses, Journal of Management and Marketing Research.

[3]. Therese A. Joiner , Total quality management and Performance The role of organization support and co-worker support, International Journal of Quality Reliability ManagementVol. 24 No. 6, 2007,pp. 617-627.

[4]. Alireza Shahraki, et all, HRM effects on TQM, Business Management Dynamics Vol.1, No.3, Sep 2011, pp.01-12

[5]. Alexandros G. Psychogios, Quality Management Practices in a Civil Service Context: Towards a Contingency Framework of TQM application, A.Psychogios-TVC-2007,P1

[6]. The Application Guide for The Deming Prize 2013 For Companies and Organizations Overseas

[7]. Alireza Shahraki, et all, HRM effects on TQM, Business Management Dynamics Vol.1, No.3, Sep 2011, pp.01-12

[8]. Sayyed Mohsen Allameh et al. /Studying the relationship between transformational leadership and psychological empowerment of teachers in Abade Township, Procedia - Social and Behavioral Sciences 31 (2012) 224 - 230,P225

[9]. M.H. Morton, P. Montgomery / Children and Youth Services Review 34 (2012) 417-425 Empowerment-based non-formal education for Arab youth: A pilot randomized trial

[10]. T M Williams ,Empowerment vs risk management?: International Journal of Project Management Vol. 15, No. 4, pp. 219-222, 1997

[11]. S. Nauman et al. / International Journal of Project Management 28 (2010) 638-649Patterns of empowerment and leadership style in project environment

[12]. $\quad{ }^{1}$ Amarjit Gill, Alan B. Flaschner, Smita Bhutan, The Impact of Transformational Leadership and Empowerment on Employee Job ,Stress, Business and Economics Journal, Volume 2010: BEJ-3

[13]. C. Cheung et al. Relocating empowerment as a management concept for Asia / Journal of Business Research 65 (2012) 36-41

[14]. T.H. Sigler, C.M. Pearson / Journal of Quality Management 5 (2000) 27 \pm 52 Creating an empowering culture: examining the relationship between organizational culture and perceptions of empowerment

[15]. Weichun Zhu and All Relationships between Transformational and Active Transactional Leadership

[16]. and Followers' Organizational Identification: The Role of Psychological Empowerment , Institute of Behavioral and Applied Management/2012,P 190

[17]. Sayyed Mohsen Allameh et al. /Studying the relationship between transformational leadership and psychological empowerment of teachers in Abade Township, Procedia - Social and Behavioral Sciences 31 (2012) 224 - 230,P225

[18]. T.H. Sigler, C.M. Pearson / Journal of Quality Management 5 (2000) 27 \pm 52 Creating an empowering culture: examining the relationship between organizational culture and perceptions of empowerment

[19]. Weichun Zhu and All Relationships between Transformational and Active Transactional Leadership and Followers' Organizational Identification: The Role of Psychological Empowerment , Institute of Behavioral and Applied Management/2012,P 190

[20]. Feigenbaum, A.V. (1961), Total Quality Control, McGraw-Hill, New York, NY

[21]. Crosby, P.B. (1979), Quality Is Free, McGraw-Hill, New York, NY.

[22]. Oakland, J., 1993. Total quality management: The route to improving performance. London: Butterworth

[23]. Edward Sallis ,Total Quality Management in Education, Kogan Page Ltd,Third edition ,2002. 